\title{
Aplicações do óleo residual de fritura visando à mitigação de impactos ambientais: uma revisão integrativa
}

\section{Gabrielle Cruz Monteiro Sousa ${ }^{1}$, Caio de Oliveira Pinto ${ }^{1}$, Débora Carvalho da Silva Oliveira ${ }^{1}$, Luana Kelly de Jesus Santos $^{1}$, Mariana Simões Queiroz ${ }^{1}$, Paulo Gabriel Ferreira de Azevedo ${ }^{1}$ e Luiz Antônio Pimentel Cavalcanti ${ }^{2}$}

\author{
${ }^{1}$ Instituto Federal de Educação, Ciência e Tecnologia da Bahia. Curso de Graduação \\ em Engenharia Química. Campus Salvador. Rua Emídio dos Santos S/№. Barbalho. \\ Salvador-BA, Brasil (CEP 40301-015). \\ ${ }^{2}$ Instituto Federal de Educação, Ciência e Tecnologia da Bahia. Campus Salvador. \\ Rua Emídio dos Santos S/№. Barbalho. Salvador-BA, Brasil (CEP 40301-015). \\ E-mail: luiz.cavalcanti@ifba.edu.br.
}

Resumo. Com o aumento exponencial da população mundial, aumentou-se também a geração de resíduos provenientes da alimentação humana. Estima-se que no Brasil são produzidos, por ano, cerca de 3 bilhões de litros de óleo vegetal destinados à alimentação, sendo que, apenas aproximadamente $1 \%$ desse valor é descartado corretamente após o uso, enquanto todo o resto é lançado sem um devido tratamento na natureza. 0 óleo residual proveniente do processo de fritura acarreta diversos problemas ao meio ambiente quando descartado incorretamente, causando a poluição dos corpos hídricos e prejudicando seus ecossistemas. Nessa perspectiva, o presente trabalho teve como objetivo apresentar rotas alternativas para a reutilização do óleo residual de fritura (ORF), bem como avaliar a aplicabilidade desse resíduo como insumo para geração de novos produtos, visando a contribuir para a mitigação dos impactos ambientais causados pelo descarte inadequado. Foi realizada uma revisão bibliográfica integrativa abrangendo trabalhos que abordavam a reutilização do óleo residual de fritura, totalizando 49 estudos elencados, entre os anos de 2006 a 2021, indexados nas bases de dados Google Scholar, Scielo e Science Direct. Dentre os quais, 26 foram selecionados para a apresentação dos resultados durante a discussão, destacando-se os estudos que apresentavam a aplicabilidade do óleo residual de fritura na produção de biodiesel, sabão, vela artesanal, ceras e graxas, biolubrificantes, massa de vidraceiro, resinas e na ração animal. Os resultados apresentados neste artigo evidenciaram que a reutilização do ORF como insumo para geração de novos produtos é um caminho viável para a diminuição dos impactos ambientais causados pelo seu descarte inadequado, além de ser uma alternativa para
Recebido

$24 / 08 / 2021$

Aceito

$27 / 11 / 2021$

Disponível on line

$28 / 11 / 2021$

Publicado

$31 / 12 / 2021$

Acesso aberto

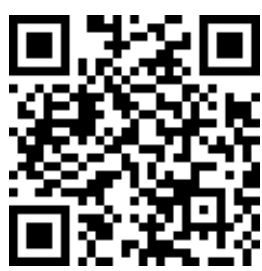

(D) 0000-0001-6622-649X

Gabrielle Cruz

Monteiro Sousa

D 0000-0001-8021-2430 Caio de Oliveira Pinto

ISSN 2359-1412/RBGAS-2021-0108/2021/8/20/12/1441

Rev. Bras. Gest. Amb. Sustent.

http://revista.ecogestaobrasil.net 
agregar valor a este resíduo, fazendo-se necessário uma maior atenção à logística da coleta, como também um maior estudo sobre sua aplicabilidade em algumas rotas, como na produção de ceras e graxas.

Palavras-chave: Óleo residual de fritura; Reutilização; Impactos ambientais.

Abstract. Residual frying oil applications aiming at mitigation exponential increase in the world population, the generation of waste from human food has also increased. It is estimated that in Brazil, around 3 billion liters of vegetable oil are produced per year for food, and only approximately $1 \%$ of this amount is properly disposed of after use, while everything else is released without proper treatment in nature. Residual oil from the frying process causes several problems to the environment when improperly disposed of, causing pollution of water bodies and harming their ecosystems. In this perspective, the present work aimed to present alternative routes for the reuse of residual frying oil (RFO), as well as to evaluate the applicability of this residue as an input for the generation of new products, aiming to contribute to the mitigation of the environmental impacts caused by inappropriate disposal. An integrative literature review was carried out, covering works that addressed the reuse of residual frying oil, totaling 49 studies listed, between the years 2006 to 2021, indexed in the Google Scholar, Scielo and Science Direct databases. Among which, 26 were selected to present the results during the discussion, highlighting the studies that presented the applicability of residual frying oil in the production of biodiesel, soap, handmade candles, waxes and greases, biolubricants, putty, resins and in animal feed. The results presented in this article showed that the reuse of RFO as an input for the generation of new products is a viable way to reduce the environmental impacts caused by its inadequate disposal, in addition to being an alternative to add value to this waste, making it necessary greater attention to the logistics of collection, as well as greater study of its applicability in some routes, such as in the production of waxes and greases.

Keywords: Waste cooking oil; Reuse; Environmental impacts.
๑) 0000-0003-0987-724X

Débora Carvalho da

Silva Oliveira

(D) 0000-0002-7092-647X

Luana Kelly de Jesus

Santos

(D) 0000-0002-8339-6527

Mariana Simões

Queiroz

(D) 0000-0003-0685-2928

Paulo Gabriel Ferreira de Azevedo

D 0000-0003-4932-9387

Luiz Antônio Pimentel

Cavalcanti

\section{Introdução}

A crescente poluição ambiental causada por fatores antrópicos é uma problemática que cresce exponencialmente a cada ano, acompanhando o aumento populacional e diretamente associada à negligência do ser humano no que tange o descarte dos dejetos, sejam domésticos quanto industriais, segue a uma velocidade e quantidade que a natureza não consegue processar de maneira natural, causando o desequilíbrio e a degradação do meio ambiente. 
Os óleos vegetais que são amplamente empregados nas casas e restaurantes, após serem utilizados, se tornam potenciais poluentes na condição de óleo residual de fritura, pois caso este resíduo não apresente a destinação correta podem seguir através dos esgotos para rios e mares. 0 óleo é imiscível e mais leve que a água, o que faz com que se crie uma película de óleo na superfície da água este fato leva a poluição dos cursos hídricos dificultando, encarecendo ou até impossibilitando o seu tratamento para consumo e também criando barreiras que dificultam a entrada de luz e a oxigenação da água impactando negativamente a fauna e flora aquática (Montenegro et al., 2013; Simões et al., 2016).

0 reaproveitamento deste subproduto é possível havendo aplicabilidade como insumo de outros produtos, como por exemplo, o biodiesel. Porém ainda não se tem um planejamento eficaz que acompanhe a velocidade da geração do óleo residual, fato este que se evidencia inicialmente na ausência de uma política de educação ambiental para informar a população sobre a sua correta destinação. Outra problemática que já é evidenciada no fluxo de reaproveitamento é o preço do óleo residual que o profissional de reciclagem recebe frente a outros produtos recicláveis (Veloso et al., 2012).

Ao realizar um levantamento de preços ao entrar em contato com diversas empresas de coletas por todo o Brasil, observa-se que o preço do litro do óleo de fritura é comprado de $R \$ 1,00$ a $R \$ 2,00$ a depender da região do Brasil, sendo o preço médio de $\mathrm{R} \$ 1,50$. Já os materiais mais popularmente reciclados, como cobre misto e alumínio (lata de alumínio), chegaram em 2021 a valores médios de $\mathrm{R} \$ 25,00$ e $\mathrm{R} \$ 6,50$, respectivamente. Esta disparidade nos preços acaba desestimulando o trabalhador da reciclagem a trabalhar com o óleo residual.

0 preço dos materiais recicláveis está diretamente relacionado à sua demanda como insumo e a variabilidade de rotas de produção a qual ele pode ser aplicado. A disseminação de pesquisas divulgando as alternativas para a aplicabilidade do óleo residual como insumo para fabricação de outros produtos pode influir no aumento da demanda, impactando diretamente nos preços e, consequentemente, tornando a sua coleta mais atrativa para os profissionais da área.

Nessa perspectiva, o presente trabalho tem como objetivo apresentar possibilidade de aplicações para o óleo residual de fritura visando a contribuir para a mitigação dos impactos ambientais causados pelo seu descarte indevido, bem como apontar possíveis rotas para agregar valor comercial ao resíduo.

\section{Metodologia}

0 presente trabalho visa a levantar uma revisão bibliográfica integrativa dos trabalhos relacionados ao reuso do óleo residual de fritura nos processos de diversos produtos. Para tal, foram feitas pesquisas e foram levados em consideração trabalhos entre 2006 e 2021. Para busca dos trabalhos foram usados os descritores "óleo de fritura", "óleo residual de fritura", "reaproveitamento do óleo de fritura", "reuso do óleo de fritura", em português, espanhol e inglês, nas plataformas Google Scholar, Science Direct e Scielo.

\section{Resultados e discussão}

Devido ao incremento na geração de óleo residual de fritura, e visando a propor alternativas de aplicação deste resíduo, de forma a minimizar os impactos ambientais causados pela incorreta destinação, bem como apontar caminhos para geração de incentivos sociais e econômicos. No presente trabalho foram investigados e incluídos 26trabalhos, apresentando diversas aplicações ambientalmente amigáveis do óleo residual como matéria-prima, como a fabricação de biodiesel, sabão artesanal, massa de vidraceiro, vela artesanal, ceras e graxas, ração animal, biolubrificante e resinas. 
Durante a pesquisa, foram avaliados 47 trabalhos, sendo excluídos 23, por não corresponderem com o objetivo do presente trabalho. Como critério de inclusão, foram considerados trabalhos que referem-se ao uso do óleo residual de fritura na produção de outros produtos, conferindo ao primeiro uma rota alternativa ao descarte. 24 trabalhos foram incluídos na revisão. A relação de trabalhos incluídos é exibida na Tabela 1.

Tabela 1. Relação de trabalhos incluídos na revisão integrativa.

\begin{tabular}{|c|c|}
\hline Autor e data & Objetivo \\
\hline Almeida et al. (2018) & $\begin{array}{l}\text { Preparar sabão com propriedades fitoterápicas, com o intuito de dar } \\
\text { uma destinação mais adequada a este resíduo, incentivando a } \\
\text { comunidade local a reutilizá-lo na fabricação de um produto com } \\
\text { propriedades medicinais. }\end{array}$ \\
\hline Bakovic et al. (2006) & $\begin{array}{l}\text { Alterar o óleo virgem utilizado em massa de vidraceiro por ORF e } \\
\text { avaliar suas propriedades e viabilidade econômica. }\end{array}$ \\
\hline Batista (2020) & $\begin{array}{l}\text { Avaliar os efeitos proporcionados por uma dieta de alto grão e uma } \\
\text { dieta com inclusão de } 6 \% \text { de óleo de fritura no desempenho, } \\
\text { características da carcaça, qualidade da carne e custos de produção de } \\
\text { cordeiros criados em confinamento. }\end{array}$ \\
\hline Bertê et al. (2014) & $\begin{array}{l}\text { Produzir sabão líquido e em barra, buscando reutilizar o ORF, e } \\
\text { incentivar a preservação do meio ambiente. }\end{array}$ \\
\hline Campos (2009) & $\begin{array}{l}\text { Avaliar o efeito devido a inclusão do óleo de fritura residual sobre o } \\
\text { consumo, desempenho e características de carcaça de Tourinhos } \\
\text { Rednorte terminados em confinamento. }\end{array}$ \\
\hline Cecilia et al. (2020) & $\begin{array}{l}\text { na revisão do processo de produção de biolubrificante: desafios e } \\
\text { rspectivas futuras. }\end{array}$ \\
\hline Enciso (2021) & $\begin{array}{l}\text { Elaborar um plano de negócios para avaliar a viabilidade da } \\
\text { fabricação, comercialização e exportação de velas decorativas } \\
\text { produzidas com cera de soja para os Estados Unidos. }\end{array}$ \\
\hline Hernandez et al. (2016) & $\begin{array}{l}\text { Tendência de patenteamento de Biolubrificantes: Visão do potencial de } \\
\text { inovação. }\end{array}$ \\
\hline Macedo et al. (2021) & $\begin{array}{l}\text { Obtenção de biolubrificante por epoxidação etílica de óleo de soja } \\
\text { residual. }\end{array}$ \\
\hline Marchezan et al. (2014) & $\begin{array}{l}\text { Reutilizar o ORF na fabricação de sabonete em barra com essência de } \\
\text { cravo-da-índia, visando à preservação do meio ambiente. }\end{array}$ \\
\hline McNutte He- (2015) & $\begin{array}{l}\text { Desenvolvimento de biolubrificantes partindo de óleos vegetais via } \\
\text { modificação química. }\end{array}$ \\
\hline Montes (2016) & $\begin{array}{l}\text { Dimensionar um sistema capaz de produzir tinta de impressão de } \\
\text { sistemas offset, utilizando uma resina obtida de óleo residual de } \\
\text { fritura. }\end{array}$ \\
\hline $\begin{array}{l}\text { Nascimento e Cavalcanti } \\
\text { (2018) }\end{array}$ & $\begin{array}{l}\text { Produzir biodiesel a partir de misturas binárias de óleo residual e óleo } \\
\text { vegetal em um reator alimentado por energia solar }\end{array}$ \\
\hline Oliveira (2015) & $\begin{array}{l}\text { Dimensionar um sistema para reciclagem de óleo de fritura para a } \\
\text { produção de sabão e resinas poliméricas, desde a realização do } \\
\text { pré-tratamento do resíduo recebido até a obtenção dos produtos } \\
\text { finais. }\end{array}$ \\
\hline $\begin{array}{l}\text { Oliveira e Nakamura } \\
(2016)\end{array}$ & $\begin{array}{l}\text { Confeccionar velas aromatizadas e coloridas, como alternativa simples } \\
\text { e segura de reutilização do ORF, visando aincentivar a conscientização } \\
\text { e educação ambiental. }\end{array}$ \\
\hline Oliveira et al. (2017) & $\begin{array}{l}\text { Avaliar o comportamento ingestivo de ovinos que foram alimentados } \\
\text { com dietas de diferentes concentrações de óleo residual de fritura. }\end{array}$ \\
\hline
\end{tabular}


Tabela 1. Continuação.

\begin{tabular}{|l|l|}
\hline Autor e data & Objetivo \\
\hline Peixoto et al. (2017) & $\begin{array}{l}\text { Avaliar o consumo e a digestibilidade de determinados nutrientes, o } \\
\text { balanço de nitrogênio e o nitrogênio amoniacal ruminal em cordeiros } \\
\text { de dietas abrangendo diferentes níveis de óleo residual de fritura. }\end{array}$ \\
\hline Rodrigues et al. (2021) & $\begin{array}{l}\text { Produzir sabão e vela utilizando o ORF juntamente com a comunidade } \\
\text { local, visando à conscientização e àapresentação de alternativas para } \\
\text { sua reutilização. }\end{array}$ \\
\hline Rossi et al. (2018) & $\begin{array}{l}\text { Produzir biodiesel a partir do óleo de soja refinado, óleo de soja } \\
\text { residual sem tratamento e óleo residual tratado. }\end{array}$ \\
\hline Scarpino et al. (2014) & $\begin{array}{l}\text { Avaliar o efeito da inclusão de duas fontes lipídicas diferentes (óleo de } \\
\text { soja e óleo de soja residual) na dieta de ovinos em confinamento nos } \\
\text { parâmetros sanguíneos. }\end{array}$ \\
\hline Silva e Puget (2010) & $\begin{array}{l}\text { Aprimorar métodos de produção de sabão já existentes utilizando ORF, } \\
\text { visando àotimizar o método de produção, e efetuá-lo com baixo custo, } \\
\text { para a obtenção de um produto de qualidade. }\end{array}$ \\
\hline Thode Filho et al. (2014) & $\begin{array}{l}\text { Apresentar a produção de bioprodutos a partir do ORF, com a intenção } \\
\text { de apresentar alternativas de sua aplicação para reduzir os impactos } \\
\text { ambientais. }\end{array}$ \\
\hline Veloso et al. (2012) & Apresentar rotas para reutilização de óleos residuais de fritura. \\
\hline Yu et al. (2017) & $\begin{array}{l}\text { Estudo da viabilidade da produção de ceras usando óleo de rícino } \\
\text { hidrogenado. }\end{array}$ \\
\hline
\end{tabular}

\section{Biodiesel}

O biodiesel é um biocombustível constituído por ésteres de ácidos graxos e pode ser produzido a partir da reação de transesterificação de óleos vegetais ou gordura animal com um álcool de cadeia curta, geralmente metanol ou etanol, na presença de um catalisador (Vieira et al., 2015; Oliveira et al., 2021). Apesar de ter como matéria-prima principal os óleos vegetais virgens, o óleo residual proveniente do processo de fritura (ORF) tem sido apontado como uma alternativa sustentável e mais economicamente viável para a síntese de biodiesel, uma vez que, as matérias-primas representam cerca de $70 \%$ a 95\% de todo o custo envolvido na produção do biocombustível, além de possibilitar uma correta destinação para o $\mathrm{ORF}$, contribuindo para o meio ambiente e agregando valor a este resíduo (Coelho et al., 2020).

Ao passar pelo processo de fritura, o óleo é submetido a diversos fatores que levam à sua degradação, como o contato com a água, proveniente da desidratação dos alimentos quando submetidos ao processo de fritura, contato com o ar atmosférico e altas temperaturas, tais fatores podem desencadear reações de oxidação dos ácidos graxos insaturados, bem como promover a hidrólise desses compostos, alterando suas propriedades físicas, químicas e organolépticas, como o aumento do índice de acidez e mudança de coloração (Lima, 2015). A acidez elevada do óleo residual prejudica a síntese de biodiesel, levando à formação de sabão e ao maior consumo de catalisador, reduzindo assim o rendimento da reação de transesterificação. Além disso, uma acidez elevada pode causar também futuras complicações no uso do biocombustível, pois afeta diretamente sua estabilidade oxidativa, contribuindo para uma rápida auto degradação e ocasionando problemas de armazenagem e corrosão do motor (Rossi et al., 2018).

De acordo com Nascimento e Cavalcanti (2018), para óleos com valores de acidez acima de $0,5 \%$, é indicado que o triglicerídeo seja submetido a um pré-tratamento, a fim de diminuir o teor de ácidos graxos livres presentes no mesmo. A escolha do método a ser aplicado como pré-tratamento do óleo residual, bem como da melhor rota para síntese do biocombustível, dependerá do índice de acidez da matéria-prima, visando a alcançar a 
produção de um biodiesel de alto desempenho com o menor custo possível (Marins e Santos, 2017).

Visando à redução dos custos no processo de produção, Nascimento e Cavalcanti (2018) produziram biodiesel a partir de misturas binárias de óleo de soja e óleo residual em diferentes proporções, utilizando um reator sustentável alimentado por energia solar. As misturas foram realizadas em proporções de 3,5\%, 5,0\%, 10,0\%, e 16,0\% (em massa) de óleo residual adicionado ao óleo de soja refinado. Os biodiesel foram produzidos a partir do óleo de soja puro e das misturas binárias, através da reação de transesterificação alcalina homogênea, utilizando metóxido de potássio como catalisador. Os autores concluíram que a adição de óleo residual ao óleo puro é uma saída viável para redução do índice de acidez do ORF, obtendo valores abaixo de 0,5\% para até 16\% (em massa) de óleo residual adicionado à mistura, garantindo a possibilidade da produção de biodiesel com apenas uma etapa reacional. Foi constatado também que os biodiesel produzidos obtiveram bons rendimentos, todos acima de $96 \%$.

Seguindo o viés de estudo sobre a viabilidade da reutilização do ORF como matéria-prima, Rossi et al. (2018) produziram biodiesel a partir do óleo de soja refinado, óleo de soja residual sem tratamento e óleo residual tratado, a fim de comparar o potencial econômico e as características de cada biocombustível. Foram realizados dois tipos de tratamento para o óleo residual, o primeiro utilizando $\mathrm{NaCl}$ e o segundo com o processo de esterificação, empregando o dimetil-sulfato como catalisador, proveniente da dissolução do ácido sulfúrico no metanol. Os autores constataram que o método mais eficiente de tratamento foi a esterificação, reduzindo significativamente o índice de acidez do óleo residual, de 6,406 para 0,632 (mg KOH/g). Com relação aos biodiesel sintetizados, apenas a amostra produzida a partir do óleo residual sem tratamento não obteve bons resultados, com baixo rendimento e alto índice de acidez. Os autores analisaram também os custos envolvidos em cada processo e concluíram que o biodiesel produzido a partir do óleo residual de fritura tratado possui um alto potencial econômico, com $\mathrm{R} \$ 1,63 / \mathrm{kg}$.

Segundo Marins e Santos (2017), o reaproveitamento do óleo residual de fritura para produção de biodiesel poderia minimizar consideravelmente os custos envolvidos no processo de produção, além de ser uma rota alternativa para a correta destinação desse resíduo. Entretanto, de acordo com Lago (2016), um dos maiores desafios enfrentados no cenário brasileiro para que ocorra o reaproveitamento desse resíduo ainda é a falta de uma logística na coleta do óleo, que se encontra disperso em restaurantes, lanchonetes e residências. Além disso, é necessário uma capacitação para que os produtores estejam aptos a produzir o biocombustível, inviabilizando ainda mais o processo.

\section{Sabão artesanal}

Uma das aplicações mais conhecidas para o óleo residual é na fabricação de sabão artesanal, tanto pela simplicidade do processo, como pela viabilidade econômica.Nessa perspectiva, é uma das utilizações mais relatadas em projetos de educação ambiental, já que, por sua simplicidade e baixo custo, é muito empregada por iniciativas na conscientização de comunidades e estabelecimentos, não só para reutilizar o resíduo gerado, mas também como possibilidade de geração de renda (Rodrigues et al., 2021). 0 sabão é um sal de ácido graxo, sendo obtido por meio da reação de hidrólise a quente dos ésteres que constituem o ORF, em meio alcalino, onde gera-se também glicerol, reação esta conhecida como reação de saponificação (Figura 1) (Silva e Puget, 2010).

Existem diversos procedimentos na literatura para a produção do sabão, onde são variadas as quantidades de reagentes e aditivos utilizados, bem como as condições de produção. Visando aobservar a influência destes parâmetros na cadeia produtiva do sabão, para assim aprimorar sua produção, sua qualidade e custo final, Silva e Puget (2010) produziram sabão por meio de diferentes rotas, onde foram variados os tempos de 
desodorização e proporção de carvão ativado utilizado; as técnicas de produção; as quantidades dos reagentes; e o tempo reacional.<smiles>[R]C(=O)OCC(COC([R])([R])[R])OC([R])=O</smiles>

Figura 1. Reação de saponificação. Fonte: Adaptado de Silva e Puget (2010).

Os resultados obtidos pelos autores demonstraram que após uma hora de desodorização, a remoção do odor do ORF foi eficaz, quando se utilizou a proporção de 1:3 (carvão:ORF). Observou-se também que, dentre os aditivos utilizados, o que apresentou melhor resultado frente às propriedades do sabão produzido foi o sabão em pó, além de apresentar o menor custo de produção. Constatou-se também que o tempo reacional onde obtém-se um rendimento satisfatório da reação foi de $20 \mathrm{~min}$. Com base nestas informações, os autores concluíram que foi possível se obter um sabão de qualidade, com um alto rendimento $(97 \% \pm 2 \%)$ nas condições especificadas, a um baixo custo.

Bertê et al. (2014), com o objetivo de confeccionar novos produtos a partir do reaproveitamento do ORF, para assim reduzir os impactos ambientais, produziram detergente líquido, que possui maior demanda de mercado. Para isto, foram utilizados os reagentes convencionais (água, ORF e soda cáustica), e álcool comum, onde após o preparo se obteve um volume considerável de sabão líquido a um baixo custo. 0 produto foi testado por membros de uma escola pública de Santa Maria, no Rio Grande do Sul, através da aplicação deste em atividades domésticas, que atestaram que o sabão confeccionado era de boa qualidade e rendimento, comprovando assim a eficácia do método utilizado, bem como promovendo a conscientização dos membros envolvidos.

Outra aplicação do ORF é na produção de sabão fitoterápico, como abordado por Almeida et al. (2018), que realizaram estudos com o objetivo de produzir um sabão fitoterápico a ser aplicado tanto em banho de animais domésticos, como na limpeza doméstica, e que promovesse a hidratação da pele e contribuísse com a cicatrização de feridas. Para isto, os autores produziram sabão, empregando em sua composição plantas com propriedades medicinais conhecidas. Testes preliminares de $\mathrm{pH}$ realizados pelos autores revelaram que o sabão sintetizado apresentava um $\mathrm{pH}$ bastante alcalino. Com base nos resultados obtidos, foram realizados ajustes nos insumos utilizados na síntese, levando à redução do $\mathrm{pH}$. $\mathrm{O}$ sabão sintetizado foi testado pelos moradores da Vila $\mathrm{C}$, que atestaram a qualidade do mesmo. Os autores permanecem estudando a composição do sabão produzido, visando a minimizar ao máximo a alcalinidade, bem como realizando testes aspirando a um maior aproveitamento das ervas medicinais adicionadas.

Além das aplicações em sabão para uso doméstico, é possível empregar o ORF na fabricação de sabonete para higienização humana. Marchezan et al. (2014) produziram 
sabonetes utilizando ORF, com o objetivo de reutilizar este resíduo, verificar a qualidade do produto final, bem como, através da comparação entre os sabonetes produzidos com e sem a aplicação de soda cáustica em sua produção, avaliar os impactos gerados pela não utilização deste insumo nas propriedades do produto, já que, por ser destinado à higiene humana, o sabonete requer uma qualidade superior à apresentada pelos sabões retratados anteriormente, e um maior controle de sua alcalinidade. Após análises de $\mathrm{pH}$ e testes de remoção de sujidades, constatou-se que os sabonetes que utilizavam soda em sua produção apresentaram $\mathrm{pH}$ muito alto, sendo irritantes à pele. Com isso, os autores chegaram à conclusão que foi possível reutilizar o ORF para a produção de sabonete de qualidade, mesmo não utilizando soda cáustica no processo.

\section{Massa de vidraceiro}

A massa de vidraceiro (MV) é um material amplamente utilizado em construções para a fixação de vidros em molduras, impedir formação de fendas em madeiras e encher buracos de pregos. A mistura é normalmente preparada a partir de pó de gesso (sulfato de cálcio) e óleos vegetais como o óleo de linhaça. Com a finalidade de redução do custo de produção do material e evitar descarte indevido de outros insumos, pode-se substituir alguns componentes durante a síntese da massa de vidraceiro, como as cinzas volantes que podem substituir o pó de gesso, e o ORF, que apresenta a possibilidade de utilização no lugar dos óleos virgens (Bakovicet al., 2006).

Para Bakovic et al. (2006), há a possibilidade de substituição do óleo de linhaça virgem pelos $\mathrm{ORF}$, sendo encontradas na MV feita com matéria prima reutilizada (MVMPR) propriedades similares às da MV comercializada (MVC). A penetrabilidade da MVMPR teve resultados muito próximos a $\mathrm{MVC}$, tendo ainda uma taxa de endurecimento maior pela sintetizada com material reutilizado. A análise de infravermelho demonstrou também que ao longo de 6 meses não houveram mudanças significativas na composição do material. Os autores destacaram ainda a importância de calcular uma razão aproximada de óleo residual para a composição do MVMPR usando TGA, pois é necessária uma validação de maior escala para utilização do ORF.

\section{Vela artesanal}

A confecção de velas artesanais utilizando o ORF como matéria-prima é uma aplicação muito simples, e vem ganhando notoriedade tanto pela facilidade de realização, pelo baixo custo de produção, por ser uma aplicação rentável, bem como pela maior segurança em comparação com a produção de sabão artesanal (outra aplicação muito utilizada por sua simplicidade, mas que emprega soda cáustica como reagente, apresentando mais riscos em seu processo produtivo), não exigindo assim uma alta qualificação para a execução do seu processo de produção. Desta forma, este produto se apresenta como uma ótima forma de reutilização do resíduo oleoso, já que permite uma maior participação da comunidade, gerando assim renda e educação ambiental (Oliveira e Nakamura, 2016).

Thode Filho et al. (2014), visando a reduzir os impactos causados pelo descarte do óleo residual, apresentaram a obtenção da vela artesanal, onde a mesma foi produzida através da reação do ORF com estearina. Após a produção, os autores chegaram à conclusão de que a produção deste bioproduto é vantajosa, já que os utensílios utilizados são encontrados no ambiente doméstico, são utilizados reagentes simples e de fácil aquisição, e ao se comparar os custos envolvidos na produção com os custos de aquisição de uma vela comum, produzida a partir da parafina proveniente dos processos de refino do petróleo, o custo associado à vela artesanal é bem menor.

Já Oliveira e Nakamura (2016), com o objetivo de apresentar uma alternativa fácil e segura de reutilização do ORF, produziram velas artesanais aromatizadas, partindo de diferentes materiais. Para isto, os autores realizaram a confecção das velas utilizando 
estearina, parafina e cera de abelha como alternativa ambientalmente sustentável, para promover o endurecimento do produto, essência artificial e de citronela natural, e giz de cera para promover a alteração da cor do produto. Os resultados obtidos revelaram que, através da aplicação das essências natural/artificial, foi possível mascarar o odor característico do ORF, bem como o endurecimento do produto foi eficiente utilizando tanto a parafina como a cera de abelha, sendo a cera de abelha mais recomendada por ser um insumo sustentável. E com relação à coloração escura do ORF, esta pôde ser alterada através do emprego do giz de cera, onde foi possível conferir diferentes cores às velas produzidas.

A produção de velas se mostra uma aplicação muito promissora para reutilização do ORF, principalmente na produção de velas ornamentais, visto que este produto está culturalmente associado à espiritualidade/religião, e a datas comemorativas, onde são utilizados na decoração dos ambientes. Em virtude disto, este produto apresenta alto valor agregado, onde se estima que suas vendas globais correspondam a US\$ 5 bilhões/ano (Enciso, 2021). Baseando-se nisso, Enciso (2021) desenvolveu um plano de negócio com o objetivo de exportar velas ornamentais ecológicas para os Estados Unidos, produzidas a partir de matéria-prima vegetal, que além de serem ambientalmente amigáveis e não apresentarem riscos à saúde e segurança do consumidor, em comparação com as velas oriundas da parafina de petróleo, ainda apresentam um baixo custo de produção. Os resultados obtidos através da análise dos lucros e perdas revelaram a viabilidade do projeto de exportação, uma vez que os Estados Unidos apresentam uma crescente demanda neste mercado.

\section{Ceras e graxas}

De acordo com Pinheiro (2018), ceras são formadas por ésteres de cadeias longas, resultados da reação entre um álcool e um ácido, ambos graxos e com grandes cadeias. De acordo com sua origem, as ceras podem ser naturais ou sintéticas, além de desempenharem diversas funções, desde a impermeabilização de penas de aves até a produção de embalagens no ramo de alimentos (Cirillo, 2018; Pinheiro, 2018). Dentre as ceras sintéticas, sua principal origem é do refino do petróleo (Yu et al., 2017).

Não foram encontrados na literatura especializada registros de trabalhos que utilizaram o ORF como matéria-prima para ceras e graxas, entretanto essa possibilidade não pode ser descartada. Como foi visto, o ORF pode ser usado para síntese do biodiesel, de acordo com os trabalhos de Rossi et al. (2018) e de Marins e Santos (2017). Diante da similaridade entre as produções do biodiesel (triacilglicerol com álcoois de cadeias curtas) e das ceras (triacilglicerol com álcoois de cadeias longas), ambas através da transesterificação, pode-se esperar que ORF pode ser usado na síntese de ceras, tal como observado no biodiesel. Assim, como foram encontrados trabalhos avaliando a possibilidade da conversão do ORF em biodiesel, uma conclusão similar pode ser feita para as ceras.

Sobre a viabilidade de usar óleos para a produção de ceras, Yu et al. (2017) utilizou óleo de rícino hidrogenado para sintetizar cera, visando à substituição das ceras de abelha e de carnaúba em sistema de embalagens e revestimentos. Os autores utilizaram etanolamina em diferentes proporções para a reação com o óleo, formando uma cera com resultados promissores: para embalagens, foi relatado que a dureza do produto é sete vezes maior que as ceras de abelha e de carnaúba, já para revestimentos, a resistência corrosiva do produto foi maior do que as duas ceras tradicionais. Portanto, para Yu et al. (2017), o uso do óleo de rícino hidrogenado é uma interessante matéria prima para a produção de ceras com propriedades oportunas. Assim, baseando-se neste trabalho, espera-se que o ORF possa ser usado para a formação de ceras.

De acordo com Germano et al. (2020), graxas são caracterizadas pela sua viscosidade, podendo ser ésteres, gorduras etc. Portanto, apesar de não serem 
encontrados estudos de produção de graxa através do ORF na literatura, sua possibilidade pode ser considerada.

\section{Ração animal}

A adição do óleo residual de fritura na alimentação de ruminantes é uma das alternativas que vem crescendo nos últimos anos e que garante, segundo Oliveira et al. (2017), um meio de reciclar esse óleo, antes de ser descartado indevidamente na rede coletora de esgoto. Além disso, a utilização do óleo em outro setor promove o aumento de sua coleta e auxilia os catadores na obtenção de uma renda extra.

Dentre outros aspectos, existe também o fator econômico. No estudo realizado pelo IBGE 2018/2019 referente ao número efetivo de rebanhos no Brasil, notou-se que a população de ruminantes cresceu em uma taxa de aproximadamente $0,4 \%$, conforme apresentado na Tabela 2 (IBGE, 2019).

Tabela 2. Efetivo dos rebanhos e variação anual, segundo as categorias - Brasil, 2018-2019.

\begin{tabular}{|l|c|c|c|}
\hline \multirow{2}{*}{ Categorias } & \multicolumn{2}{|c|}{ Quantidade (cabeças) } & Variação anual \\
\cline { 2 - 4 } & $\mathbf{2 0 1 8}$ & $\mathbf{2 0 1 9}$ & $\mathbf{2 0 1 9} \mathbf{2 0 1 8}$ (\%) \\
\hline Grande porte & 220.950 .580 & 221.944 .135 & 0,4 \\
\hline Bovinos & 213.809 .445 & 214.659 .840 & 0,4 \\
\hline Bubalinos & 1.389 .873 & 1.434 .141 & 3,2 \\
\hline Equinos & 5.751 .262 & 5.850 .154 & 1,7 \\
\hline
\end{tabular}

Fonte: Adaptado de IBGE (2019).

Esse crescimento de bovinos apresenta como consequência direta a utilização de mais matéria-prima para alimentar os animais e por seguinte considerável aumento dos custos com alimentação. 0 principal problema deste cenário é descrito em uma pesquisa realizada por Campos (2009) que indica que dentre os principais custos com a criação de bovino, a alimentação é o indicador que se revela altamente significante, podendo ultrapassar $70 \%$ do custo total de produção, sem incluir o valor de compra do ruminante.

Esses são alguns dos motivos que beneficiaram estudos relacionados à introdução de cerca de $5 \%$ óleo residual de fritura na ração animal a alguns anos. Onde, a utilização do óleo misturado a ração tem como característica proporcionar aos mamíferos ruminantes maior eficiência de conversão alimentar, adição de vitaminas, ácidos essenciais e menor consumo de ração seca (Batista, 2020).

De acordo com a pesquisa realizada por Peixoto et al. (2017), ao inserir esse percentual de $5 \%$ de óleo residual na alimentação dos ruminantes há uma menor necessidade de consumo de matéria seca, e consequente menor quantidade de alimento é necessário para induzir o ganho de peso. Peixoto et al. (2017) também percebeu durante sua pesquisa que o valor percentual base de introdução de óleo residual na ração de animais ruminantes geralmente é de até $5 \%$, e que porcentagens maiores podem levar a mudanças na fermentação ruminal, desestabilizando o processo de conversão de alimento em energia e prejudicando a saúde do animal. No entanto, esses valores percentuais de introdução do óleo residual nas rações podem variar a depender da digestão de cada fonte de gordura, sendo o grau de insaturação o fator que mais impacta na facilidade de digestão ou não dos ácidos graxos.

Em outro estudo realizado no Rio Grande do Norte, Batista (2020) introduziu 6\% de óleo residual de fritura na alimentação de cordeiro e avaliou o desempenho do animal e 
a qualidade da carne gerada através desse tipo de alimentação híbrida (ração e óleo residual). Segundo Batista (2020), a introdução de maiores percentuais de óleo residual de fritura à ração devem ser acompanhados, tanto quanto os seus valores nutricionais, quanto os efeitos que podem ser gerados ao ambiente ruminal, sendo que a quantidade exagerada de óleo pode provocar doenças e diminuir o desempenho animal.Neste estudo, a introdução de $6 \%$ de óleo de fritura resultou no aumento produtivo e econômico e não houve mudanças físico e composição na carne perceptíveis.

Um estudo semelhante foi realizado em ovinos, onde de acordo com Scarpino et al. (2014), a introdução deste mesmo percentual de 6\% de óleo residual causou o aumento da concentração de colesterol e da enzima AST. No entanto, essas elevações não foram suficientes para prejudicarem a saúde do animal.

Esses estudos são importantes devido à possibilidade de aumentar não só a conversão alimentar como também a diminuição da ração seca, reduzindo os custos substancialmente sem interferir na digestão ou na qualidade da carne do animal e criando uma alternativa ao uso do óleo de fritura que é pouco reciclado.

\section{Biolubrificante}

Os óleos lubrificantes são substâncias que tem como finalidade a proteção do desgaste e atrito entre duas superfícies que terão contato entre si formando uma película protetora entre elas. A partir do Século XX os óleos lubrificantes provenientes de óleos minerais passaram a ser a mais comumente aplicados, porém estes além de produzirem resíduos mais poluentes ao meio ambiente possuem substâncias que são nocivas à saúde humana fato que inibe a utilização destes na indústria alimentícia ou farmacêutica, em que haja risco de contato acidental com alimento ou produto.

A Resolução ANP no 804/2019, a qual dispõe sobre os critérios para obtenção do registro de graxas e óleos lubrificantes e as responsabilidades e obrigações dos detentores de registro, produtores e importadores, traz em seu texto as especificações que os lubrificantes utilizados nestas indústrias precisam atender (Brasil, 2019) e, tendo isto em vista as especificidades que a indústria alimentícia e farmacêutica precisam atender, os biolubrificantes se apresentam como uma ótima alternativa para estes ramos por serem biodegradáveis e não tóxicos e, portanto, representam pouco ou nenhum risco para o meio ambiente ou para os humanos (McNutte He, 2015).

Para a obtenção dos biolubrificantes a partir de óleos vegetais McNutt e He(2015) apresenta três rotas através de modificação química, sendo elas a esterificação/transesterificação, a formação de estolide e a epoxidação.

A esterificação/transesterificação são as vias reacionais mais comumente utilizadas para reorganização de frações triglicerídeos provenientes dos óleos para formar novos ésteres com propriedades físicas melhoradas. Para o processo de obtenção do biolubrificante esta via reacional consiste em duas etapas principais, primeiramente os triglicerídeos reagem com um álcool de cadeia curta tendo no meio reacional um catalisador básico produzindo então ésteres metílicos de ácidos graxos. Na segunda etapa, estes ésteres metílicos resultantes são, então, reagidos com álcool, sendo possível a aplicabilidade de diversa gama de álcoois, na presença de um catalisador químico ou enzimático para produzir triésteres que o compõem, sendo este produto o biolubrificante (McNutt e He, 2015).

McNutt e He (2015) apontam que é viável utilizar como insumo desta rota resíduos de óleo de cozinha apesar de carregar adesvantagem devido a introdução de uma etapa de purificação do óleo residual.

As pesquisas com base nesta reação também destacam as diferenças na forma de processamento no que se refere à utilização do catalisador químico ou enzimático na segunda etapa, segundo McNutt e He (2015) os catalisadores enzimáticos tem vantagens sobre os catalisadores químicos por apresentarem alta seletividade e tornar as condições 
reacionais mais brandas, próximas às condições ambientes ponto importante já que esta via reacional requer temperaturas relativamente elevadas de reação e a pressão negativa.

Cecilia et al. (2020) emprega a lipase líquida em meio sem solvente no seu estudo no qual conclui ter aplicação mais vantajosa frente às enzimas imobilizadas por tratar de um processo mais econômico e ambientalmente favorável, por não usar solventes, e um processo mais rápido para a produção de ésteres de cadeia mais longa.

A alta variabilidade de álcoois que podem ser aplicados na segunda etapa possibilita a formação de diferentes biolubrificantes com propriedades diversas amplificando seu leque de aplicação. Outro benefício observado nos biolubrificantes produzidos por transesterificação é o aumento de sua estabilidade termo-oxidativa, diminuição do ponto de fluidez mantendo características como viscosidade e lubricidade em níveis apropriados para atuação do biolubrificante (McNutt e He, 2015).

Na primeira etapa da reação os ácidos graxos são produzidos através da hidrólise de triglicerídeos e, posteriormente, o produto da primeira etapa é posta a reagir com os íons hidrônios provenientes de ácidos, produzindo então os estolides os quais são formados por ácidos graxos ligados entre si. Biolubrificantes a base de estolides apresentam uma boa estabilidade oxidativa e menores pontos de fluidez (McNutt e He, 2015). No que tange às condições operacionais, esta reação requer baixas temperaturas, geralmente menores que $100^{\circ} \mathrm{C}$, o que acaba sendo uma vantagem atribuída a esta rota.

Porém no mesmo estudo observa-se que as características dos triglicerídeos são determinantes para aspectos de viscosidade. Nos casos dos estolides não modificados geralmente há necessidade de misturar com óleos vegetais modificados para uma melhora nas propriedades que auxiliam no poder de lubrificação.

A rota de epoxidação é baseada em uma reação em duas etapas. Na primeira etapa onde ocorre a remoção de ligações duplas entre dois carbonos presente na cadeia carbônica do triglicerídeo por meio de um átomo de oxigênio, que resulta em um grupo funcional epóxido onde a retirada da ligação dupla entre os carbonos da cadeia confere uma maior estabilidade termo-oxidativa aos ésteres. Posteriormente, em uma segunda etapa, estes ésteres são postos a reagir com álcoois tendo um catalisador no meio reacional o que realiza uma abertura no anel epóxido adicionando um íon hidroxila ao carbono e o oxigênio que estava presente no anel liga-se a uma outra cadeia, produzindo então, polióis que apresentam maior estabilidade térmica em comparação ao produto obtido da primeira etapa (Hernandez, 2016).

A segunda etapa da reação confere melhor viscosidade e estabilidade oxidativa e melhorias nos coeficientes de fricção e nas características de lubricidade. Devido a estes estudos procura-se melhorar as condições de processamento desta rota, no que tange a busca de melhores catalisadores e estudos da aplicabilidade de outros insumos (McNutt e He, 2015).

Em Macedo et al. (2021) é realizada a epoxidação com ácido peracético após o óleo residual ser submetido a umareação de transesterificação. 0 experimento conseguiu produzir um biolubrificante com bom índice de iodo e elevado índice de oxigênio oxirano, indicativos de boa qualidade química do biolubrificante, endossando a efetividade desta rota.

Lubrificantes são largamente utilizados no cotidiano, seja no âmbito industrial, agropecuário ou no dia a dia da população, a ampliação do uso de biolubrificantes é essencial para um desenvolvimento sustentável. Pois não há só a vantagem, frente a lubrificantes provenientes de combustíveis fósseis, da biodegradabilidade e toxicidade deste produto, mas sim no que tange todo o processo de sua fabricação, da matéria-prima até sua produção final. 


\section{Resinas}

As tintas são retratadas e exploradas pela humanidade há mais de trinta mil anos. Desde pinturas nas cavernas a pinturas corporais usadas no cotidiano das tribos ou como artifícios de empoderamento durante as guerras, há também relatos de tintas a base óleo que foram o marco da arte renascentista entre os séculos XIV e XVII. 0 advento da era fabril no século XVIII e petroquímico no século XX trouxeram outras necessidades de aplicabilidade para as tintas e de estudos relacionados à diminuição de custos de sua produção (Oliveira, 2015).

Nos últimos anos uma das soluções alternativas que vêm sendo introduzidas é a utilização de óleo residual de fritura para confecção de resinas utilizadas na fabricação de tintas e vernizes. Essas resinas ou binders são polímeros e representam a fase contínua de uma tinta necessária para a aglutinação de pigmentos, corantes, solventes e aditivos e a formação do filme aderente à superfície (Oliveira, 2015).

As propriedades dessas resinas à base de óleo de fritura, como secagem rápida e boa resistência química e física, obtidas através de reações controladas, revelam importantes características que sugerem estudos de viabilidade do uso de óleo residual de fritura neste setor de tintas e vernizes. Onde, esta secagem rápida pode ser ainda mais eficiente, desde que o composto apresente muitas instaurações ou se as ligações duplas sejam conjugadas ao invés de ligações não conjugadas, devido ao poder reativo das ligações conjugadas (Veloso et al., 2012).

De acordo com Veloso et al. (2012), a obtenção dessas resinas alquídicas pode ser efetuada através de três procedimentos de síntese: Por meio da acidólise, alcoólise ou por via ácido graxo, em que após a obtenção dessas resinas elas podem ser utilizadas na produção de tintas de parede ou de impressão ou até mesmo na produção de vernizes. 0 estudo realizado por Montes (2016), por exemplo, sugere a utilização de uma resina polimérica obtida através do óleo de fritura e que será utilizada na produção de tintas de impressão para um sistema offset que necessita de $80 \%$ da resina e $20 \%$ de pigmentos. A Figura 3 revela a etapa de acidólise.

a)<smiles>CCC(=O)OCC(COC(=O)CC)OC(=O)CC</smiles>

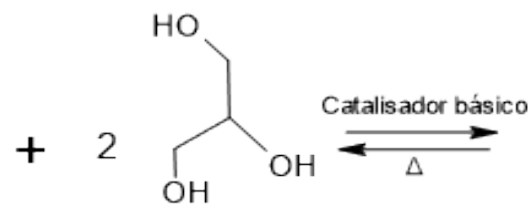<smiles>CCOC(=O)OC(CO)CO</smiles>

Tracilglicerol

Glicerol

Monoacilglicerol

b)

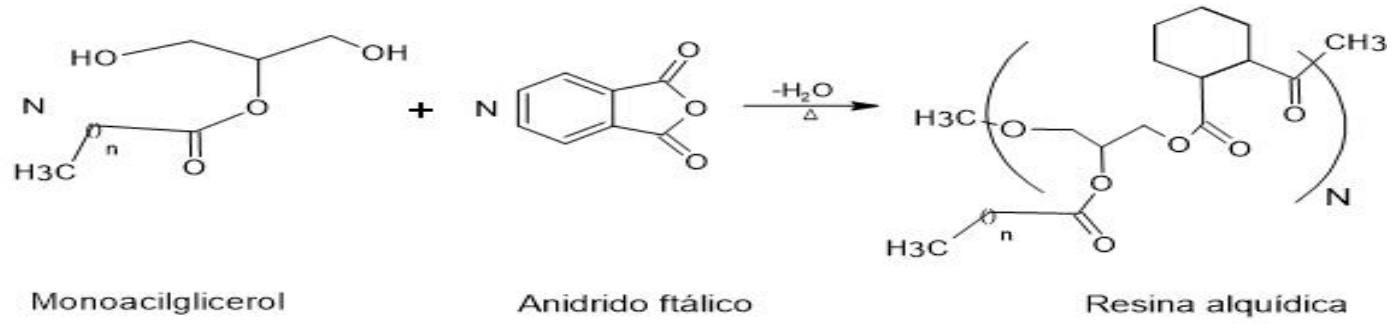

Figura 3. a) Etapa de transesterificação do óleo residual de fritura com o glicerol; b) Etapa de acidólise e formação da resina alquídica, através de poliesterificação.Onde $n$ representa a quantidade de carbonos na cadeia. Fonte: Adaptado de Oliveira (2015). 
Montes (2016) destaca que existem algumas modificações físicas e químicas durante o processo de fritura do óleo, dentre elas: Aumento da viscosidade, acréscimo do calor específico, redução do número de iodo (relacionado com as insaturações), alteração da tensão superficial, crescimento da tendência do óleo de gerar espuma, dentre outras.

Como consequência dessas alterações, o óleo de fritura necessita das reações descritas anteriormente para que o processo seja economicamente viável, como é o caso do produto gerado na alcoólise que reage na poliesterificação da resina de forma eficiente, assim como as moléculas de monoacilgliceróis utilizadas industrialmente.

\section{Conclusão}

Diante dos resultados discutidos, vê-se então que os estudos envolvendo a reutilização de óleos residuais para evitar o seu descarte indevido atrai cada vez mais atenção ao longo dos anos, e isso se deve à crescente atenção que vem sendo dada para as questões ambientais. Logo, os efeitos de sua destinação inadequada no meio ambiente, bem como soluções ambientalmente amigáveis e que visem ao maior valor agregado ao produto final, tornam-se pontos importantes de análise.

Concluiu-se então que o óleo residual pode ter diversos destinos que possibilitam sua reutilização, sendo uma das possíveis rotas seria a síntese de biodiesel, tendo enorme potencial econômico devido a diminuição dos custos envolvidos, e viabilizando um devido descarte do ORF. Outras aplicações como fabricação de sabão e vela ornamentais foram relatadas, este primeiro apresenta certa problemática, pois a manipulação em sua maior parte é realizada em ambientes sem adequado controle, inviabilizando seu uso prático devido ao $\mathrm{pH}$ alto do produto final, já as velas, em contrapartida, apresentaram resultados promissores, sendo possível mascarar o odor do ORF com essências, além de baixar o custo de produção de um produto com amplo mercado.

Ademais, constatou-se que há possibilidade de aplicação do ORF em outros produtos como massa de vidraceiro, ceras, graxas e resinas, contudo, esses materiais carecem de estudos que os relacionem com a utilização de óleos residuais, sendo que ainda em alguns como a resina, constatou-se a baixa viabilidade de reutilização, devido a alterações físicas e químicas durante o processo de fritura do óleo. As sínteses de biolubrificantes e ração animal mostraram-se rotas promissoras para a reutilização do ORF, sendo necessários mais estudos que constatem a viabilidade econômica e possibilidade de uso prático.

\section{Conflito de interesses}

Os autores declaram não haver conflito de interesses.

\section{Referências}

Almeida, L. G. G.; Simões, S. A. B.; Neves, A. K. C.; Lugo, F. M. C.; Barrios, S. B. C.; Rojas, K. L. G.; Onofrio, A. B. Preparação de sabão com propriedades fitoterápicas e emolientes a partir do óleo vegetal de cozinha. Anais da 1aㅗ Semana Integrada de Ensino, Pesquisa e Extensão, Foz do Iguaçu, 2018.

Bakovic, S.; Potgieter, J. H.; Dewaal, D.; Popovic, L. Replacing limestone and linseed oil in the synthesis of putty. Journal of Applied Sciences, v. 6, n. 5, p. 1009-1016, 2006. https://doi.org/10.3923/jas.2006.1009.1016

Batista, N. V. Avaliação de dieta alto grão e da inclusão de óleo residual de fritura na alimentação de cordeiros. Mossoró: Universidade Federal Rural do Semi-Árido, 2020. (Dissertação de mestrado). 
Bertê, M.; Fantinel, L.; Fernandes, L. S. Reaproveitamento de óleo de fritura para fabricação de sabão. Disciplinarum Scientia. Série: Naturais e Tecnológicas, v. 15, n. 2, p. 191-200, 2014.

Brasil. Resolução ANP no 804, de 20 de dezembro de 2019. Dispõe sobre os critérios para obtenção do registro de graxas e óleos lubrificantes e as responsabilidades e obrigações dos detentores de registro, produtores e importadores. Disponível em: <https://www.in.gov.br/web/dou/-/resolucao-n-804-de-20-de-dezembro-de-2019234968902 >. Acesso em: 05 ago. 2021.

Campos, F. R. Óleo de fritura residual na alimentação de Tourinhos Rednorte terminados em confinamento. Lavras: Universidade Federal de Lavras, 2009. (Dissertação de mestrado).

Cecilia, J. A.; Plata, D. B.; Saboya, R. M. A.; Luna, F. M. T.; Cavalcante Jr., C. L.; RodríguezCastellón, E. An overview of the biolubricant production process: Challenges and future perspectives. Processes, v. 8, 257, 2020. https://doi.org/10.3390/pr8030257

Cirillo, N. A. Cinética enzimática da produção de palmitato de cetila por esterificação em sistema livre de solvente. Curitiba: Universidade Federal do Paraná, 2018. (Dissertação de mestrado).

Coelho, F. L. L.; Santos, I. O.; Paixão, D. C.; Lhamas, D. E. L.; Rodrigues, G.; Suffredini, D. F. P.; Medeiros, A. C. G. Produção de biodiesel de óleo de fritura residual em um módulo didático de biodiesel. Brazilian Journal of Development, v. 6, n. 5, p. 28844-28852, 2020. https://doi.org/10.34117/bjdv6n5-363

Enciso, M. B. P. Plan de negocios para La exportación de velas decorativas a base de cera de soya hacia Estados Unidos. Bogotá: Fundación Universidad de América, 2021. (Monografía).

Germano, M. C.; Cagnon Neto, G.; Lucio, M. L. S.; Pierre, F. C. Administração da produção: estudo dos processos de fabricação de graxa. Anais da 9a Jornada Científica e Tecnológica da FATEC de Botucatu, 2020.

Hernandez, D. P. S. Tendência de patenteamento de biolubrificantes: visão do potencial de inovação. Rio de Janeiro: Universidade Federal do Rio de Janeiro, 2016. (Dissertação de mestrado).

IBGE - Instituto Brasileiro de Geografia e Estatística. Pesquisa da Pecuária Municipal. 2019. Disponível em: <https://agenciadenoticias.ibge.gov.br/agencia-detalhe-de-midia.html? view=mediaibge \&catid=2102\&id=4211>. Acesso em: 05 ago. 2021.

Lago, S. M. S. Proposta de um modelo de coleta de óleo de fritura residual no Município de Cascavel-PR. Anais do V Simpósio Internacional de Gestão de Projetos, Inovação e Sustentabilidade, São Paulo, 2016.

Lima, A. K. M. Purificação do óleo residual de fritura por carvão ativado visando à produção de biodiesel. Ponta Grossa: Universidade Tecnológica Federal do Paraná, 2015. (Trabalho de conclusão de curso).

Macedo, A. D. M.; Conceição, M. M.; Santos, J. C. O. Obtenção de biolubrificante por epoxidação etílica de óleo de soja residual. Anais do IV Congresso Nacional de Engenharia de Petróleo, Gás Natural e Biocombustíveis, Campina Grande, 2021.

Marchezan, M. P.; Rondon, J. N.; Otsubo, H. C. B.; Thomazelli Junior, I.; Ítavo, L. C. V.; Peruca, R. D.; Souza, A. P.; Fabri, J. R. Produção de sabonetes sólidos com óleo usado e essência de cravo-da-índia. Revista Eletrônica em Gestão, Educação e Tecnologia Digital, v. 18, n. 1, p. 577-582, 2014. https://doi.org/10.5902/2236117012684

Rev. Bras. Gest. Amb. Sustent., 2021, vol. 8, n. 20, p. 1441-1457. 
Marins, D. S.; Santos, M. E. Pré-tratamento do óleo residual de fritura para elevação do $\mathrm{pH}$ e diminuição de sólidos para a produção de biodiesel. Revista da União LatinoAmericana de Tecnologia, n. 5, p. 1-20, 2017.

McNutt, J.; He, Q. Development of biolubricants from vegetable oils via chemical modification. Journal of Industrial and Engineering Chemistry, v. 36, 2015. https://doi.org/10.1016/j.jiec.2016.02.008

Montes, P. R. Sistema para produção de tinta de impressão utilizando resina obtida de óleo residual. Brasília: Universidade de Brasília, 2016. (Trabalho de conclusão de curso).

Montenegro, M. A.; Pereira, M. C.; Gatti T. H.; Martins, G. B. C.; Suarez, P. A. Z. Aproveitamento de óleos e gorduras residuais para obtenção de produtos de alto valor agregado: formulação de tinta de impressão a partir de óleo residual de fritura. Revista Virtual de Química, v. 5, n. 1, p.26-37, 2013. https://doi.org/10.5935/19846835.20130004

Nascimento, F. A.; Cavalcanti, L. A. P. Produção de biodiesel a partir de misturas de óleos residuais e de soja em reator a energia solar. Revista CIATEC-UPF, v. 10, p. 43-52, 2018.

Oliveira, A. L. B.; Monteiro, E. M. M.; Faturi, C.; Rodrigues, L. F. S.; Domingues, F. N.; Rêgo, A. C. Comportamento ingestivo de ovinos alimentados com dietas contendo óleo de fritura residual. Revista de Ciências Agrárias, v.60, n.1, p.90-95, 2017. https://doi.org/ 10.4322/rca.60104

Oliveira, D. C. S.; Azevedo, P. G. F.; Cavalcanti, L. A. P. Processos biológicos para o tratamento de efluentes: uma revisão integrativa. Revista Brasileira de Gestão Ambiental e Sustentabilidade, v. 8, n. 18, p. 397-415, 2021. https://doi.org/10.21438/ rbgas(2021)081826

Oliveira, G. G. C.; Nakamura, A. K. S. Confecção de velas aromatizadas e coloridas a partir da utilização do óleo vegetal residual como incentivo à educação ambiental. Revista Online de Extensão e Cultura Realização, v. 3, n. 6, p. 40-50, 2016.

Oliveira, S. C. Dimensionamento de um sistema de reciclagem de óleo de fritura para produção de sabão e resinas poliméricas. Brasília: Universidade de Brasília, 2015. (Trabalho de conclusão de curso).

Pinheiro, D. M. L. Estudo do processo de produção de cera vegetal do tipo IV na Indústria Agrocera - Russas/CE. Mossoró: Universidade Federal Rural do Semi-Árido, 2018. (Trabalho de conclusão de curso).

Peixoto, E. L. T.; Monteiro, E. M. M.; Faturi, C.; Rodrigues, L. F. S.; Domingues, F. N.; Rêgo, A. C. Residual frying oil in the diets of sheep: Intake, digestibility, nitrogen balance and ruminal parameters. Asian-Australasian Journal of Animal Sciences, v. 30, n. 1, p. 51-56, 2017.

Rodrigues, P. C. S.; Vercílio, O. E.; Souza, B. M. P; Anjos, L. E. F.; Sá, P. E. Técnicas de reciclagem de óleo residual de fritura: ressignificando a produção de sabão e vela. Brazilian Journal of Development, v. 7, n. 6, p.64187-64197, 2021. https://doi.org/ 10.34117/bjdv7n6-684

Rossi, G. Z.; Borges, I. R.; Perego, T. F.; Toledo, V. D. M.; Ferreira, L. F. P. Análise técnica da produção do biodiesel a partir do óleo de fritura residual. The Journal of Engineering and Exact Sciences, $\quad$ v. 4, n. 1, p. 101-108, 2018. https://doi.org/10.18540/ jcecvl4iss1pp0101-0108 
Scarpino, F. B. O.; Ezequiel, J. M. B.; Silva, D. A. V.; Van Cleef, E. H. C. B. Óleo de soja e óleo de soja residual em dietas para ovinos confinados: parâmetros sanguíneos. Journal Scielo, v. 63, n. 241, p. 207-210, 2014. https://doi.org/10.4321/S0004-05922014000100022

Silva, B. G.; Puget, F. P. Sabão de sódio glicerinado: produção com óleo residual de fritura. Enciclopédia Biosfera, Centro Científico Conhecer, v. 6, n. 11, 2010.

Simões, A. L. C.; Pereira, L. Q.; Lima, I. C. A.; Nobre, C. P.; Dolinsky, M. C. B.; Stonyo, E. M.; Gomes, L. F. S. Reaproveitamento de óleo residual de fritura para obtenção de produtos de alto valor agregado. Anais do XIII Congresso Nacional de Meio Ambiente de Poços de Caldas, Poços de Caldas, 2016. Disponível em: <http://www.meioambientepocos.com.br/ anais-2016>. Acesso em: 06 ago. 2021.

Thode Filho, S. T.; Costa, A. P. S.; Rodrigues, I.; Sena, M. F. M.; Silva, E. R. Bioprodutos a partir do óleo vegetal residual: vela, giz e massa de modelar. Revista Eletrônica em Gestão, Educação e Tecnologia Digital, v. 18, p. 14-18, 2014. https://doi.org/10.5902/ 2236117013803

Veloso, Y. M. S.; Freitas, L. F. L.; Amaral Filho, J. H. B.; Santos, I. T.; Leite, M. S.; Araújo, P. J. L. Rotas para reutilização de óleos residuais de fritura. Cadernos de Graduação - Ciências Exatas e Tecnológicas, v. 1, p. 2-9, 2012.

Vieira, S. P.; Nascimento, F. A.; Braz, M. A.; Andrade Júnior, S. J.; Cavalcanti, L. A. P. Reuso de latinhas de alumínio recicláveis para tratamento de águas residuais da produção de biodiesel via eletrofloculação. Revista Brasileira de Gestão Ambiental e Sustentabilidade, v. 2, n. 3, p. 145-151, 2015. https://doi.org/10.21438/rbgas.020307

Yu, X.; Wang, N.; Zhang, R.; Zhao, Z. Simple synthesis hydrogenated castor oil fatty amide wax and its coating characterization. Journal of Oleo Science, v. 66, n. 7, p. 659-665, 2017. https://doi.org/10.5650/jos.ess16213

Informação da Licença: Este é um artigo Open Access distribuído sob os termos da Licença Creative Commons Attribution, que permite uso irrestrito, distribuição e reprodução em qualquer meio, desde que a obra original seja devidamente citada. 